\title{
Change in gene expression profiles of secreted frizzled-related proteins (SFRPs) by sodium butyrate in gastric cancers: Induction of promoter demethylation and histone modification causing inhibition of Wnt signaling
}

\author{
HYUNSOO SHIN ${ }^{1}$, JIE-HYUN KIM ${ }^{1}$, YEO SONG LEE ${ }^{1,2}$ and YONG CHAN LEE ${ }^{1,2}$ \\ ${ }^{1}$ Department of Internal Medicine, Institute of Gastroenterology, ${ }^{2}$ Brain Korea 21 Project for Medical Science, \\ Yonsei University College of Medicine, Seoul, Republic of Korea
}

Received October 31, 2011; Accepted December 20, 2011

DOI: $10.3892 /$ ijo.2012.1327

\begin{abstract}
Activation of Wnt signaling without mutation of $\beta$-catenin or APC occurs frequently in human gastric cancers. Secreted frizzled-related protein (SFRP), a negative modulator of the Wnt signaling pathway, are frequently inactivated in human gastric cancers. Inhibition of SFRP gene expression may account for the $\mathrm{Wnt} / \beta$-catenin activation in human gastric cancer. However, the molecular mechanisms of silencing of SFRP genes are not fully understood. Sodium butyrate, a histone deacetylase (HDAC) inhibitor, is known to exhibit anti-cancer effects partly through the differentiation of various cancer cells. In the present study, we investigated: i) the relationship between the silencing of SFRP genes and Wnt signaling; ii) the mechanism of sodium butyrate mediated epigenetic regulation of SFRPs expression in human gastric cancer. We observed that nuclear $\beta$-catenin was significantly increased in gastric cancer tissues as compared to adjacent non-cancerous tissues. Nuclear $\beta$-catenin accumulation and SFRP promoter methylation in human gastric cancer cells were noted. Treatment with the DNA methyltransferase inhibitor, 5'-Aza-2-deoxycytidine (5'-Aza-dC) rapidly restored SFRPs expression. Sodium butyrate $(\mathrm{NaB})$ induced demethylation and histone modification at the promoter region of SFRP1/2 restoring the SFRP expression in human gastric cancer cells. Analysis of general expression revealed that overexpression of SFRPs repressed Wnt target gene expression and induced changes in the proliferation and apoptosis related genes in human gastric cancer cells. These data suggest that aberrant epigenetic modification of SFRP genes is one of the major mechanisms by which Wnt signaling is activated in human gastric cancer cells and sodium butyrate may modulate
\end{abstract}

Correspondence to: Dr Yong Chan Lee, Department of Internal Medicine, Yonsei University College of Medicine, 134 ShinchonDong, Seodaemun-Ku, Seoul 120-752, Republic of Korea

E-mail: leeyc@yuhs.ac

Key words: DNA methylation, histone modification, SFRP, sodium butyrate, Wnt signal the SFRP1/2 expression through histone modification and promoter demethylation causing anti-tumor effects.

\section{Introduction}

Epigenetic mechanisms have crucial roles in the control of gene activity and nuclear architecture. The most widely studied epigenetic modification in humans is the cytosine methylation of DNA within the dinucleotide CpG; 3-6\% of all cytosines are methylated in normal human DNA (1). Silencing of cancerassociated genes by hypermethylation of $\mathrm{CpG}$ islands within the promoter regions is a common feature of human cancer and is often associated with partial or complete transcriptional block (2). Histone modifications are another key player in epigenetics (3). Promoter CpG-island hypermethylation in cancer cells is known to be associated with a particular combination of histone marks: deacetylation of histones $\mathrm{H} 3$ and $\mathrm{H} 4$, loss of histone $\mathrm{H} 3$ lysine $\mathrm{K} 4$ (H3K4) trimethylation, and gain of H3K9 methylation and $\mathrm{H} 3 \mathrm{~K} 27$ trimethylation $(4,5)$. Histone modifications are recognized as playing a crucial role in regulation of gene expression and chromatin structure and are closely involved with DNA methylation. These processes have been shown to be involved in the inactivation of many tumor suppressor genes $(6,7)$.

Two Wnt signaling pathways have been elucidated: the canonical and non-canonical pathways. Activation of the canonical pathway is mediated by $\beta$-catenin and the non-canonical pathway by $\beta$-catenin independent factors. Generally, in the absence of signal stimulation, $\beta$-catenin protein is destabilized by a cytoplasmic complex containing the proteins Axin, adenomatous polyposis coli (APC), and glycogen synthase kinase-3 $\beta$ $($ GSK-3 $\beta)(8,11)$. Activation of Wnt signaling results in accumulation of stabilized $\beta$-catenin, which activates transcription of target genes via a complex with T-cell factor/lymphocyte enhancing factor families of transcription factor (TCF/LEF) after nuclear translocation $(9,12)$. On the other hand, the canonical Wnt signaling pathway is negatively regulated by a multitude of soluble factors in the extracellular milieu. These include: Wnt inhibitory factor 1 (WIF1), secreted Frizzled related proteins (SFRPs), and Dickkopf (DKK) family of secreted proteins, which antagonize Wnt signaling by binding to LRP5/6 component (co-receptors for Frizzled) of the Wnt receptor complex 
(9). WIF1 encodes a secreted protein with a unique and highly conserved WIF domain and five epidermal growth factor-like repeats, which bind to Wnt proteins and inhibits their activities (10). In humans, the SFRP family consists of 5 members, each containing a cysteine-rich domain (CRD) which shares 30-50\% sequence homology with the CRD of Frizzled receptors (13-15). In addition to sequestrating Wnt ligands, SFRPs also downregulate the Wnt signaling pathway by the formation of inhibitory complex with Frizzled receptors (13-15).

Sodium butyrate $(\mathrm{NaB})$, a short chain fatty acid, occurs naturally in the body from the acetyl-CoA dependent catabolic oxidation of long chain saturated fatty acids $(16,17)$. Sodium butyrate as a histone deacetylase (HDAC) inhibitor is known to exhibit anti-cancer effects via the differentiation of various carcinoma cells (18-21). In this study, we aimed at elucidation of the epigenetic mechanism involved in SFRP expression, and the effect of sodium butyrate on SFRP expression in human gastric cancer cells.

\section{Materials and methods}

Cell culture and treatments. A total of nine human gastric cancer cell lines (AGS, KatoIII, MKN28, MKN45, MKN74, NCI-N87, SNU-1, SNU-16, and NCI-N87) were obtained from Korean Cell Line Bank (Korea) and American Type Culture Collection (Manassas, VA, USA). Cells were cultured in RPMI-1640 medium (Hyclone Laboraloties, Inc. USA) containing $10 \%$ fetal bovine serum (Hyclone) and $1 \%$ penicillin streptomycin sulfate (Hyclone) at $5 \% \mathrm{CO}_{2}, 37^{\circ} \mathrm{C}$ and $95 \%$ humidity.

Sodium butyrate, 5'-Aza-2-deoxycytidine (5'-Aza-dC), and Trichostatin A were purchased from Sigma-Aldrich (St. Louis, $\mathrm{MO})$. Working concentrations used were as follows: butyrate, $2 \mu \mathrm{M}$; 5-Aza-dC, $2 \mu \mathrm{M}$; and Trichostatin A, $200 \mathrm{nM}$ respectively.

Tissue samples and immunohistochemistry. Surgical specimens were obtained from 20 patients with gastric cancer with associated clinical information. The cases were provided by the Gastrointestinal Tumor Working Group Tissue Bank, Yonsei University Medical Center (Seoul, Korea) between December 1996 and December 2004. Authorization for the use of tissue for research purposes was obtained from the Institutional Review Board of Yonsei University Health System. Tissue sections in micro-slides were deparaffinized with xylene, hydrated in serial dilutions of alcohol, and immersed in $3 \% \mathrm{H}_{2} \mathrm{O}_{2}$. Following antigen retrieval in citrate buffer ( $\mathrm{pH}$ 6.0), the tissue sections were incubated with protein blocking agent (Immunotech, Coulter, Inc, Marseille, France) to block non-specific antibody binding for $20 \mathrm{~min}$ at room temperature and then incubated overnight at $4^{\circ} \mathrm{C}$ with respective primary polyclonal goat antibodies against human $\beta$-catenin (Santa Cruz). After washing with PBS three times, the sections were incubated with a biotinylated secondary antibody (goat anti-rabbit IgG, Immunotech) and streptavidin conjugated to horseradish peroxidase (Immunotech) for $20 \mathrm{~min}$ at room temperature, followed by a PBS wash. The chromogen was developed for 5 min with liquid 3,3'-diaminobenzidine (Immunotech). Next, slides were counterstained with Meyer's hematoxylin. Expression status was quantified by scoring both the intensity and proportion of $\beta$-catenin staining. The intensity of nuclear $\beta$-catenin staining was scored as 0 , negative (weak or similar to background); 1, weak (less intense than normal cells); 2, moderate (similar intensity to normal cells); and 3, strong (stronger than normal cells). The proportion of expression in each tissue was determined by counting positively stained cancer cells in relation to a total of three hundred cells, and expressing the result as a percentage.

RNA isolation, reverse transcription, polymerase chain reaction. Total RNA from human gastric cancer cells were prepared using TRIzol reagent (Invitrogen). The RNA was reverse transcribed using oligo (dT) primers and Superscript ${ }^{\mathrm{TM}}$ II reverse transcriptase (Invitrogen, Carlsbad, CA, USA). Primers used for PCR amplification of this cDNA were for SFRP1: forward 5'-TCA TGC AGT TCT TCG GCT TC-3' and reverse 5'-CCA ACT TCA GGG GCT TCT TCT TC-3'; SFRP2: forward 5'-TCT CCT ACA AGC GCA GCA AT-3' and reverse 5'-GAA CTT CTT GGT GTC CGG GT-3'; $\beta$-actin: forward 5'-TTG CCG ACA GGA TGC AGA AG-3' and reverse 5'-AGG TGG ACA GCG AGG CCA GG-3'. PCR reactions were employed using PCR Maxi kit (iNtRON, Sungnam, Korea). PCR reactions in the linear range of amplification were analyzed by agarose gel electrophoresis and quantified by densitometry if needed.

Methylation analysis. Genomic DNA was extracted from cell lines and gastric tissues by a DNeasy Blood \& Tissue kit (Qiagen, Valencia, CA, USA). Methylation status of SFRP1/2 genes in gastric tissue and human gastric cell lines were determined by methylation specific polymerase chain reaction (MSP). Briefly, $2 \mu \mathrm{g}$ of genomic DNA was bisulphite-treated with Zymo DNA Modification Kit (Zymo Research, Orange, CA, USA). Bisulphite-treated DNA was amplified using primers specific for either methylated or unmethylated DNA under the following condition: $95^{\circ} \mathrm{C}$ for $15 \mathrm{~min}$; 42 cycles of $95^{\circ} \mathrm{C}$ for 1 $\min , 55^{\circ} \mathrm{C}$ for $1 \mathrm{~min}$ and $72^{\circ} \mathrm{C}$ for $1 \mathrm{~min}$; and a final extension $4 \mathrm{~min}$ at $72^{\circ} \mathrm{C}$. The sequence of methylated specific (M) primer and unmethylated specific (U) primer for SFPR1/2 were: SFRP1 (M), forward 5'-TGT AGT TTT CGG AGT TAG TGTCGC GC-3' and reverse 5'-CCT ACG ATC GAA AAC GAC GCG AAC G-3'; SFRP1 (U), forward 5'-GTT TTG TAG TTT TTG GAGTTA GTG TTG TGT-3' and reverse 5'-CTC AAC CTA CAA TCA AAA ACA ACA CAA ACA-3'; SFRP2 (M), forward 5'-GGG TCG GAG TTT TTC GGA GTT GCG C-3' and reverse forward 5'-CCG CTCTCT TCG CTA AAT ACG ACT CG-3'; SFRP2 (U), forward 5'-TTT TGG GTT GGA GTT TTT TGG AGT TGT GT-3' and reverse 5'-AAC CCA CTC TCT TCA CTA AAT ACA ACT CA-3'. CpGenomet universal methylated DNA (Chemicon International Inc., CA, USA) was used as positive control for methylation and water was used as a negative control CpGenome universal methylated DNA (Chemicon).

Western blot analysis. Prepared cells were harvested after washing with PBS. Collected cells were lysed with buffer [50 mM Tris-Cl (pH 7.5), $150 \mathrm{mM} \mathrm{NaCl,} 1 \mathrm{mM}$ EDTA (pH 8.0), $1 \%$ Triton $\mathrm{X}-100,1 \mathrm{mM}$ PMSF, $1 \mathrm{mM} \mathrm{Na}_{3} \mathrm{VO}_{4}$, and protease inhibitor cocktail (Roche Molecular Biochemicals, Indianapolis, IN, USA)]. Fractionation was performed by sequential extraction of cytosolic and nuclear proteins in nonionic detergent for analysis of $\beta$-catenin. The same amount of protein was boiled at $95^{\circ} \mathrm{C}$ after adding SDS sample buffer [62.5 mM Tris- $\mathrm{Cl}$ (pH 6.8), 2\% sodium dodecyl sulfate, $10 \%$ 
glycerol, $\beta$-mercaptoethanol, and $0.002 \%$ bromophenol blue]. Samples were loaded in 12\% SDS-PAGE gels for SFRP1/2, 10\% SDS-PAGE gels for $\beta$-catenin and then transferred to PVDF membranes (Amersham Biosciences, Pisctaway, NJ, USA). AntiSFRP1 (Santa Cruz), Anti-SFRP2 (Santa Cruz), anti- $\beta$-catenin (Santa Cruz) was used as the primary labeling antibodies and the appropriate horseradish peroxidase-conjugated antibodies (Santa Cruz) were used as secondary antibodies. An enhanced chemiluminescence detection system (ECL-Plus, iNtRON) was used for the detection according to the manufacturer's protocol.

TCF/LEF reporter assay. Reporter assays with pGL3-OT, a TCF/LEF-responsive luciferase reporter plasmid, and pGL3OF, a negative control plasmid, were carried out as described previously (22). Briefly, cells ( $1 \times 10^{4}$ cells/well in 12-well plates) were transfected with $100 \mathrm{ng}$ of pGL3-OT or pGL3-OF and $2 \mathrm{ng}$ of pGL-TK using Lipofectamine 2000 (Invitrogen). For co-transfection experiments, cells were transfected with $500 \mathrm{ng}$ of pCMV-HA-SFRP1 or pCMV-HA-SFRP2 vectors kind gift by Dr H. Suzuki (Department of Internal Medicine, Sapporo Medical University) plus the reporter plasmid. Firefly and renilla luciferase activities were measured $48 \mathrm{~h}$ the after transfection using a Dual-Luciferase Reporter Assay System (Promega, Madison, WI, USA) according to the manufacturer's instruction.

Flow cytometry. Cells were treated with $2 \mu \mathrm{M}$ sodium butyrate (Sigma), $2 \mu$ M 5'-Aza-dC (Sigma), and $200 \mathrm{nM}$ Trichostatin A (Sigma) for $48 \mathrm{~h}$, replacing the drug and medium every $24 \mathrm{~h}$. Prepared cells were harvested after washing with PBS. Collected cells were lysed with $1 \mathrm{X}$ binding buffer (BD Bioscience, USA). Then, $100 \mu \mathrm{l}$ of the lysate were transferred to a 5-ml culture tube and treated with FITC Annexin V and PI (BD Bioscience) for $15 \mathrm{~min}$ at $25^{\circ} \mathrm{C}$ in dark. The cell cycle distribution was determined using a FACScan flow cytometer (Becton-Dickinson, Mountain View, CA, USA) and 10,000 cells were analysed with MultiCycle software package (Phoenix, San Diego, CA, USA).

Cell proliferation assay. Cells were seeded in 96-well plates. Cells were treated with $2 \mu \mathrm{M}$ sodium butyrate (Sigma), $2 \mu \mathrm{M}$ 5'-Aza-dC (Sigma), and $200 \mathrm{nM}$ Trichostatin A (Sigma) for $48 \mathrm{~h}$, replacing the drug and medium every $24 \mathrm{~h}$. The colorimetric MTTs (Promega) assay was used to measure viable cell numbers at $48 \mathrm{~h}$. Experiments were performed in triplicates.

Immunofluorescence microscopy. Cells cultured on chamber slides were washed with phosphate buffered saline (PBS) and fixed with $10 \%$ formaldehyde, after which they were incubated with anti- $\beta$-catenin monoclonal antibody, anti-SFRP1 and anti-SFRP2 (Santa Cruz) and stained with anti-mouse IgG-FITC (Santa Cruz), anti-goat IgG-TR (Santa Cruz). Cells were visualized using a Zeiss LSM 510 confocal laserscanning microscope (Carl Zeiss, USA).

Chromatin immunoprecipitation (ChIP) assay. ChIP analysis was done using ChIP assay kit (Upstate Biotechnology, Inc.) according to the manufacturer's instructions. AGS and MKN45 cells were used. Immunoprecipitation was done overnight at $4^{\circ} \mathrm{C}$ with $10 \mu \mathrm{l}$ of the sample used as the input, or $1 \mu \mathrm{g}$ of $\mathrm{AcH} 3$ (AcH3, 06-599, Upstate Biotechnology, Lake Placid, NY,
Table I. Expression of nuclear $\beta$-catenin in human gastric cancer.

\begin{tabular}{lccr}
\hline & \multicolumn{3}{c}{$\beta$-catenin } \\
\cline { 2 - 4 } & Positive rate $^{\mathrm{b}}$ & Intensity $^{\mathrm{c}}$ & P-value $^{\mathrm{a}}$ \\
\hline $\begin{array}{l}\text { Adjacent non-cancer } \\
\text { tissue }\end{array}$ & $30 \%(3 / 10)$ & $33.2 \pm 47.8$ & $<0.05$ \\
Cancer tissue & $70 \%(7 / 10)$ & $45.6 \pm 63.8$ & $<0.05$ \\
\hline
\end{tabular}

${ }^{\text {a }}$ Pearson's v2 test. ${ }^{\mathrm{b}}$ The positive rate of expression was determined by counting the number of tissues to have positively stained cancer cells in 10 specimens of each tissue. ${ }^{\circ}$ The intensity was scored as 0 , no detectable nuclear staining; 1 , weak nuclear staining; or 2, strong nuclear staining. The number of positively stained cancer cells in relation to a total of a hundred cells was multiplied by the intensity score $(0,1$ or 2$)$, and then was added up (mean $\pm \mathrm{SD})$.

USA), AcH4 (AcH4, 06-866, Upstate Biotechnology), H3K4 (07-030, Upstate Biotechnology), H3K9 (AB1220, Abcam, Cambridge, MA, USA) or the negative control mouse IgG, positive control anti-RNA polymerase beads. After reverse cross-linking, DNA was purified with QIAquick PCR purification kit (Qiagen) from the immunoprecipitates.

Primers were designed to separately amplify regions in the SFRPs promoter are SFRP1: forward, 5'-GTT GGA GCT GTT TGC TGT GA-3' and reverse, 5'-ATG TTT TGG CTT TCC ACA CC-3'; SFRP2: forward, 5'-AAA AAG GCC AAG AAA ACT CT-3' and reverse, 5'-CGG AGT TCG AGC TTG TCC-3' (46).

Statistical analysis. Statistical significance was evaluated using Student's t-test and Pearson's $\chi^{2}$ test for immunohistochemistry, Student's t-test for luciferase activity, cell apoptosis, proliferation and a One-way ANOVA with multiple comparison tests for densitometry analysis. $\mathrm{P}<0.05$ was considered statistically significant. To confirm the induction results, experiments were repeated at least three times. All statistical analyses were carried out using SPSS 12.0 software (SPSS, Chicago, IL, USA).

\section{Results}

Wnt signaling pathways in human gastric cancer cell lines and tissues. To evaluate the Wnt signal expression in gastric cancer tissues, immunohistochemical staining was carried out for 20 paraffin-embedded surgical specimens. All specimens were obtained from gastric cancer patients with American Joint Committee on Cancer (AJCC) TNM stage I or II. Nuclear $\beta$-catenin expression was higher in cancer tissues than adjacent non-cancerous tissues (Fig. 1A and Table I). We also determined the correlation between $H$. pylori infection and SFRP1/2 methylation from the endoscopically biopsied clinical tissues. H. pylori infection was detected in gastric cancer tissues irrespective of methylation status of SFRP1/2 genes. There was no association between promoter hypermethylation of SFRP1/2 gene and the status of $H$. pylori infection. In addition, there was no significant association between SFRP1/2 methylation and the clinicopathological characteristics of cancer including age, sex, and 
A

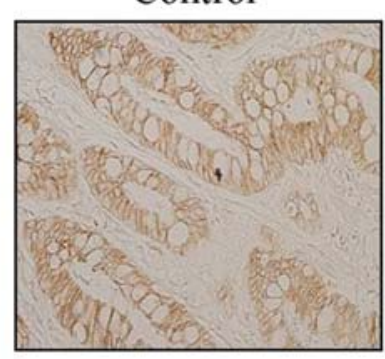

$\beta$-catenin

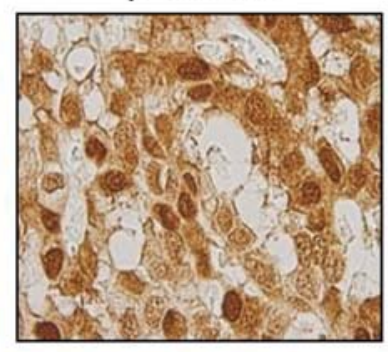

B
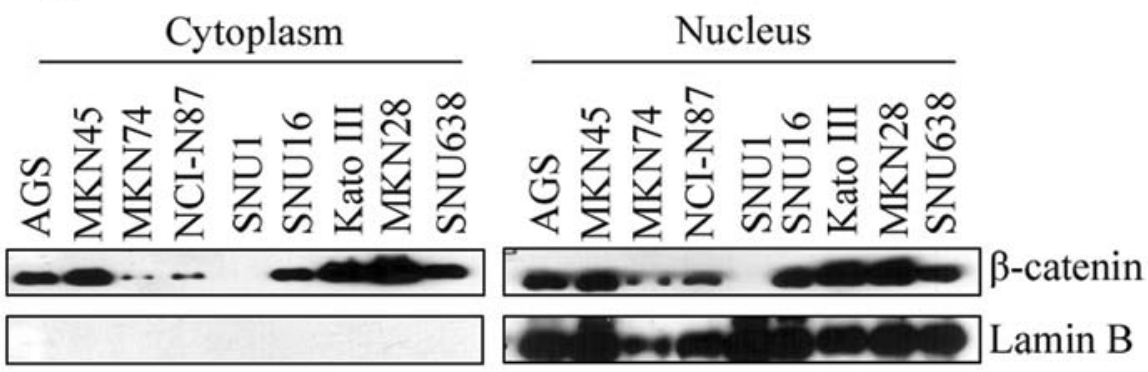

Figure 1. Comparison of Wnt pathway activities in human gastric cancer cell lines. (A) Immunohistochemical staining for $\beta$-catenin in gastric carcinoma tissues. Nuclear $\beta$-catenin staining was stronger in control than in cancerous tissues. Magnification x400. (B) Western blot analysis for $\beta$-catenin was carried out after sequential extractions of cytosolic and nuclear proteins from cells in non-ionic detergent. Lamin B1 (a nuclear protein) and $\beta$-actin were used as internal standards.

Table II. Patient characteristics and methylation status.

\begin{tabular}{cccccccccc}
\hline & & & & & \multicolumn{2}{c}{ SFRP1 } & & \multicolumn{2}{c}{ SFRP2 } \\
\cline { 6 - 7 } \cline { 5 - 6 } Patient & Sex & Age & H.pylori & N & C & & N & C \\
\hline 1 & F & 67 & Pos & - & + & + & + \\
2 & F & 81 & Pos & - & + & + & + \\
3 & M & 67 & Neg & - & + & - & + \\
4 & F & 37 & Pos & + & + & + & + \\
5 & F & 58 & Neg & + & + & - & + \\
6 & M & 86 & Pos & + & - & + & - \\
7 & M & 64 & Pos & + & + & + & + \\
8 & M & 73 & Pos & - & + & - & + \\
9 & F & 70 & Pos & - & + & + & + \\
10 & F & 69 & Pos & + & - & + & + \\
11 & M & 69 & Pos & + & - & - & + \\
12 & F & 50 & Pos & + & + & + & + \\
13 & F & 64 & Neg & + & + & + & - \\
14 & M & 71 & Pos & - & + & + & + \\
15 & M & 69 & Pos & + & + & - & + \\
\hline
\end{tabular}

SFRPs, the role of secreted frizzled-related proteins; C, cancer; $\mathrm{N}$, adjacent non-cancer; + , methylation; pos, positive; neg, negative. Methylation status determined by methylation specific PCR.

prognosis for patients (Table II). To investigate activation of the canonical Wnt signaling pathway in human gastric cancer cell lines, the expression of nuclear $\beta$-catenin proteins was assessed by Western blotting after sequential extraction of cytosolic and nuclear proteins from cells (Fig. 1B). We found expression of nuclear $\beta$-catenin in eight of the nine cells, although the levels of expression varied among the cell lines (Fig. 1B). Thus, these finding suggest the involvement of mechanisms other than alterations in gene expression of APC or $\beta$-catenin in the activated of Wnt signaling in human gastric cancer.

Expression and methylation status of SFRPs in human gastric cancer cell lines. The down-regulation of SFRP gene expression may also contribute to the activation of Wnt signaling in human gastric cancer cell lines. We first used reverse transcriptase polymerase chain reaction (RT-PCR) to analyse SFRP expression in human gastric cancer lines. Surprisingly, none of the nine human gastric cancer cell lines tested showed any expression of SFRP1/2 mRNA. On the other hands treatment with a DNA methyltransferase inhibitor, 5'-Aza-dC rapidly restored SFRPs expression, strongly indicating the epigenetic silencing of SFRP1/2 in human gastric cancer cells (Fig. 2A). The expression of SFRP1/2 in human gastric cancer cells also increased after $\mathrm{NaB}$ treatment (Fig. 2B). These findings suggest that sodium butyrate treatment may also induce promoter demethylation of SFRP genes in human gastric cancer cells. To this end, we examined the status of SFRP promoter methylation. Our methylation specific PCR (MS PCR) analysis indeed revealed the methylation of SFRP1/2 in all 9 human gastric cancer cell lines (Fig. 2C). These findings suggest that loss of SFRP gene expression is strongly associated with DNA methylation in human gastric cancer cell lines.

Decreased nuclear $\beta$-catenin by sodium butyrate. To investigate the changes in expression pattern of nuclear $\beta$-catenin by epigenetic modifiers in human gastric cancer cells, the nuclear $\beta$-catenin expression was assessed by Western blotting after sequential extraction of cytosolic and nuclear proteins from cells. The expression of nuclear $\beta$-catenin decreased without 
A

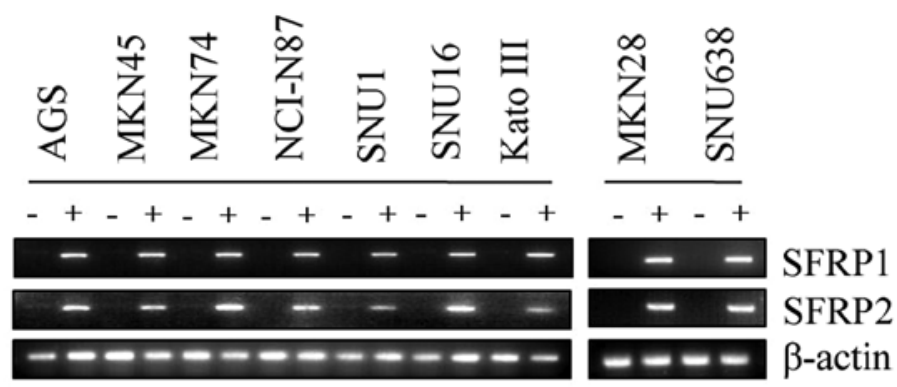

B
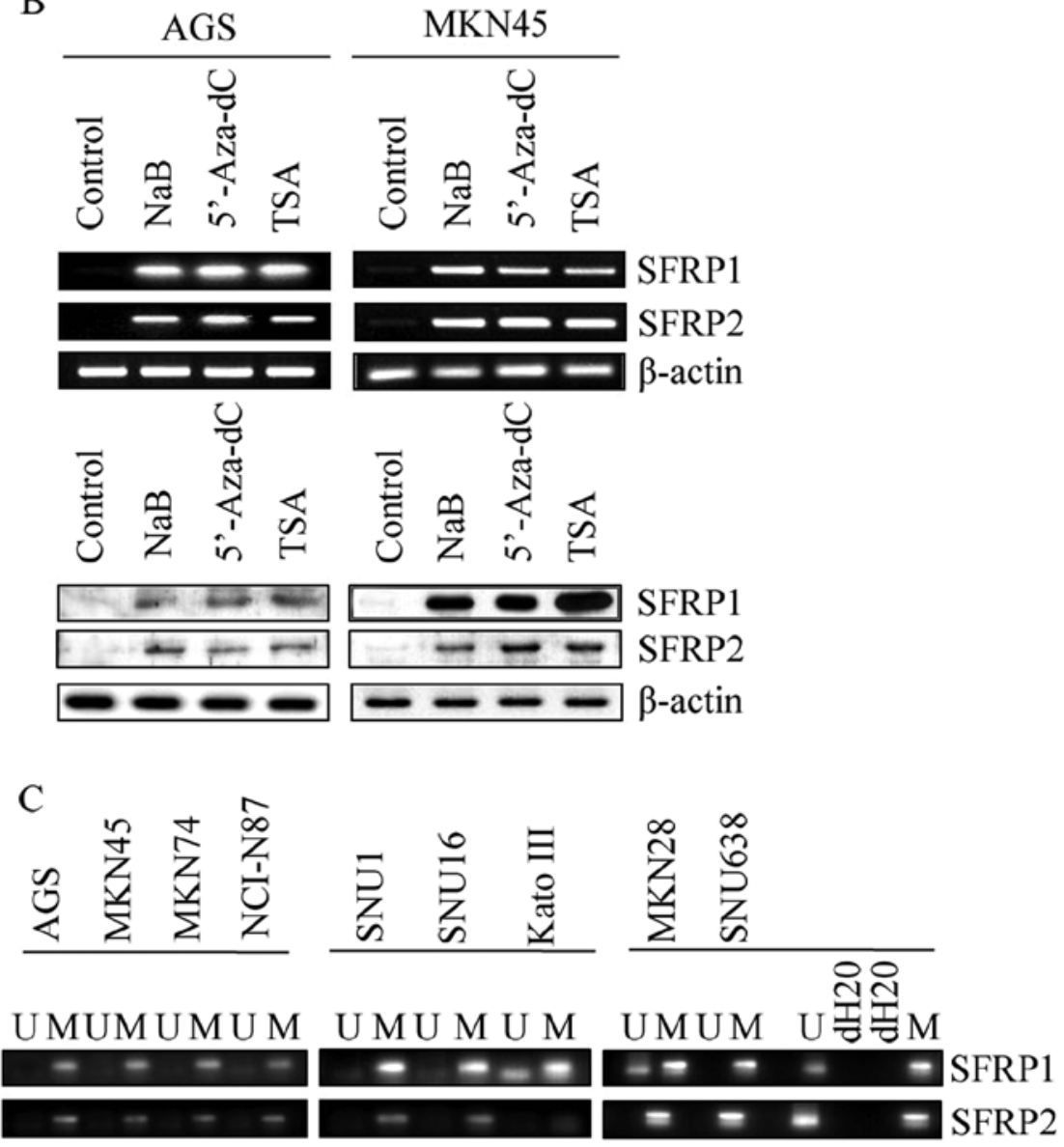

Figure 2. Analysis of SFRP gene expression in the indicated human gastric cancer cell lines. (A) RT-PCR analysis of SFRP1/2 expression in the indicated human gastric cancer cell lines, with or without treatment with 5-Aza-dC. RT-PCR for $\beta$-actin was carried out for all samples to ensure cDNA quality. (B) Expression of SFRP1/2 due to sodium butyrate treatment (NaB) in human gastric cancer cells (AGS, MKN45). RT-PCR (upper) and Western blotting (lower) were carried out with $\beta$-actin as an internal standard. (C) Analysis of SFRP1/2 methylation in GC cell lines. Representative results from MSP analysis of the indicated human gastric cancer cell lines. Bands in the M lanes are PCR products obtained with methylation-specific primers; those in the U lanes are products obtained with unmethylated-specific primers.

a change in cytoplasmic $\beta$-catenin during treatment with $\mathrm{NaB}$, 5'-Aza-dC, TSA in human gastric cancer cells (Fig. 3A). When TCF/LEF-regulated transcriptional activity in human gastric cancer cells were analysed using a TCF/LEF-responsive luciferase reporter vector (pGL3-OT), we found that the luciferase activity of pGL3-OT were more than twofold higher that of pGL3-OF, a negative control vector (Fig. 3B). Treatment with $\mathrm{NaB}, 5$ '-Aza-dC and TSA significantly inhibited pGL3-OT activity. These findings indicated that effective inhibition of Wnt signal in human gastric cancer cells was achieved through the epigenetic regulation.
Effect of sodium butyrate on SFRPs promoter methylation and histone modification. To investigate the role of histone modification in the epigenetic inactivation of the SFRPs genes, we examined histone acetylation and methylation pattern in the chromatin associated with the SFRP1/2 promoter region using ChIP assay. The histone-associated DNAs, immunoprecipitated with antibodies against $\mathrm{AcH} 3, \mathrm{AcH} 4, \mathrm{H} 3 \mathrm{~K} 4$ and $\mathrm{H} 3 \mathrm{~K} 9$, were individually amplified with primer covering the SFRP $1 / 2$ promoter regions (Fig. 4A). The ChIP assay showed marked increase in the levels of histone modification of SFRP1/2 gene in human gastric cancer cells. As sodium butyrate is a well 
A
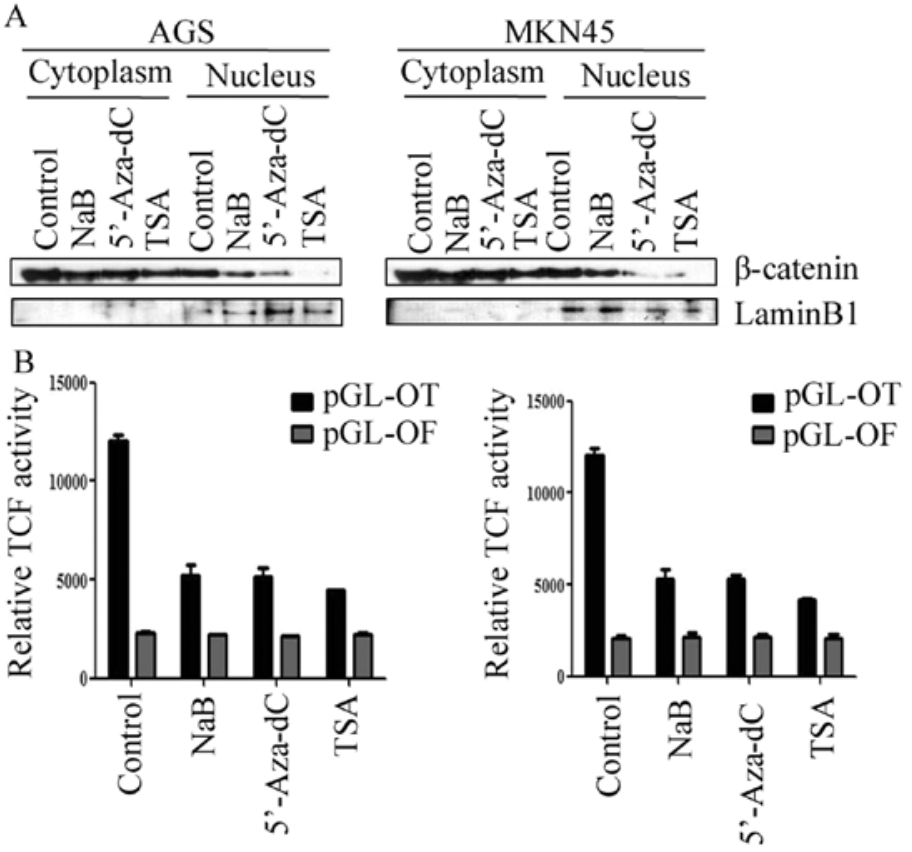

Figure 3. Decreased nuclear $\beta$-catenin expression after sodium butyrate treatment in human gastric cell lines. (A) Western blotting for $\beta$-catenin was carried out after sequential extractions of cytosolic and nuclear proteins from cells in non-ionic detergent. Lamin B1 (a nuclear protein) and $\beta$-actin were used as internal standards. (B) Luciferase assay was carried out using a TCF/LEF responsive reporter (pGL3-OT) and a negative control (pGL3-OF). Results are expressed as the pGL3-OT/pGL3-OF activity ratio after correction for transfection efficiency using renilla luciferase activity. The means of four replications are shown; the error bars represent standard deviations.

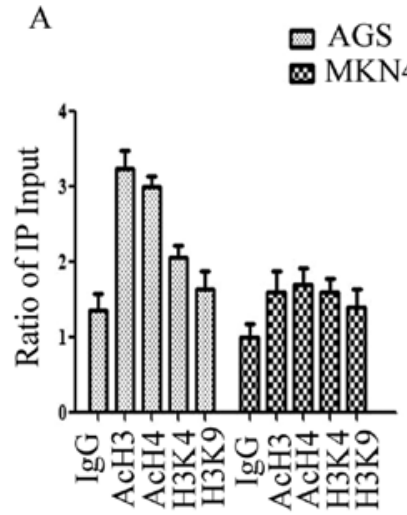

SFRP1

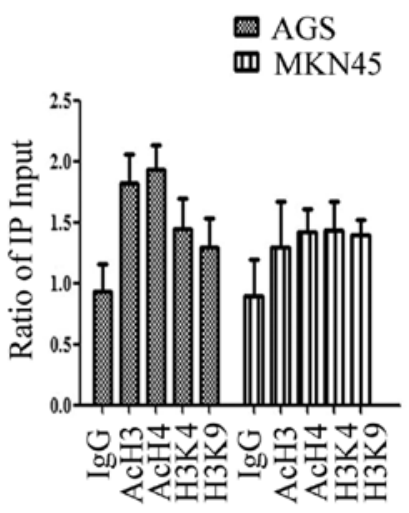

SFRP2

B

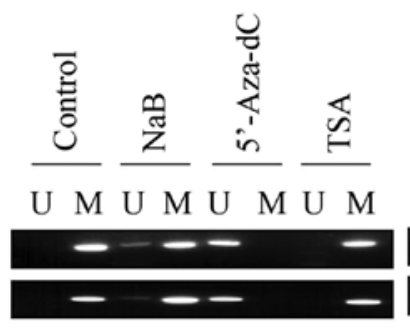

SFRP1

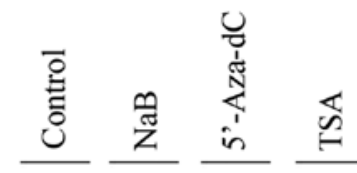

$\mathrm{U} M \mathrm{M} \mathrm{U} \mathrm{M} \mathrm{U} \mathrm{M}$

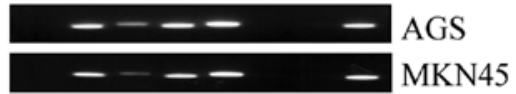

SFRP2

Figure 4. Effects of sodium butyrate on SFRP promoter methylation and histone modification. (A) Representative ChIP-PCR analyses in human gastric cancer cells treated with sodium butyrate (NaB). Chromatin DNA was immunoprecipitated with antibodies for acetyl-H3 (AcH3), acetyl-H4 (AcH4), dimethyl-H3K4 (H3K4) and dimethyl-H3-K9 (H3K9). Quantification of ChIP-PCR results. Vertical bars represent the ratios of PCR products with immunoprecipitated DNA (IP) versus input DNA. Error bars denote standard deviation. Each ChIP was repeated twice, and duplicate PCRs were performed on each ChIP DNA sample to confirm the reproducibility of results. (B) The methylation statuses of SFRPs in human gastric cancer cells treated with sodium butyrate, 5'-Aza-dC, or TSA as determined through methylation-specific PCR. Bands in the M lanes are PCR products obtained with methylation-specific primers; those in the U lanes are products obtained with unmethylated-specific primers. 
A
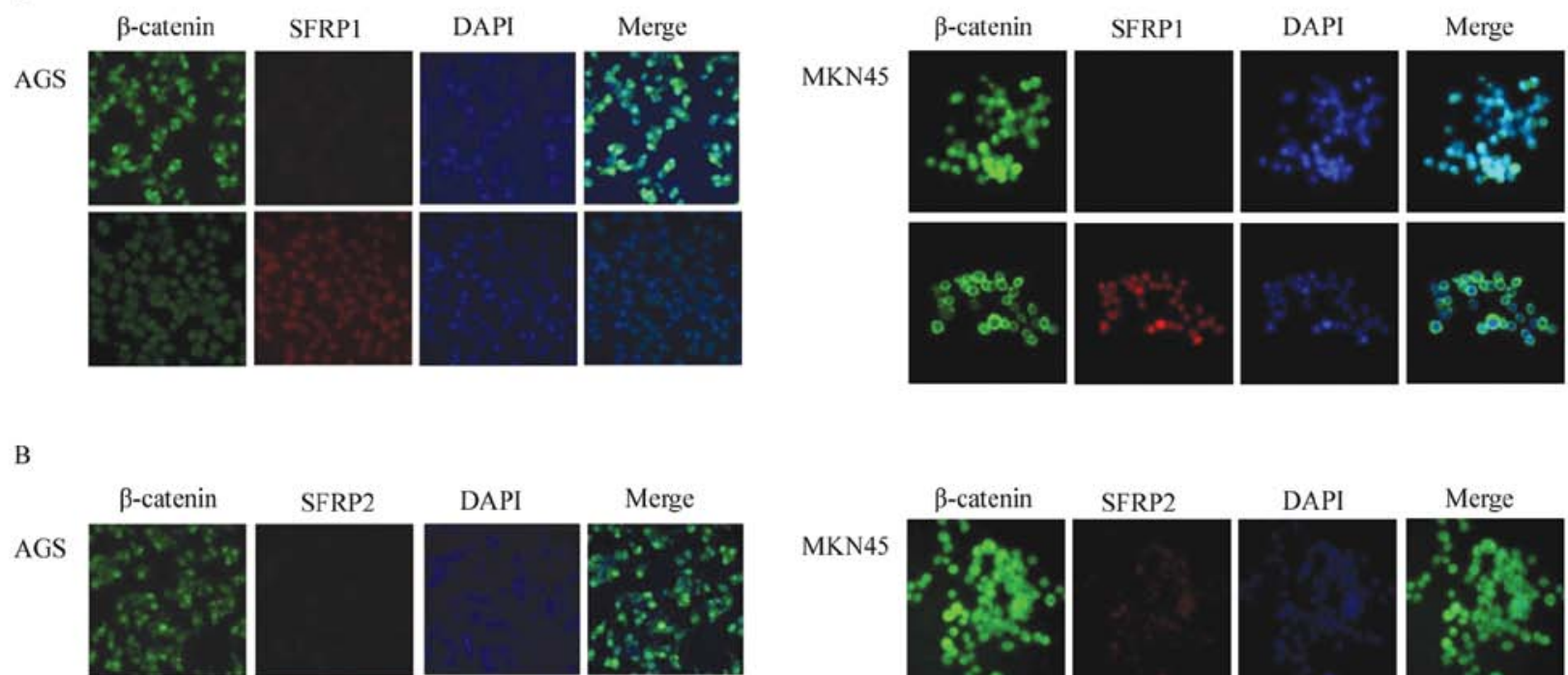

DAPI

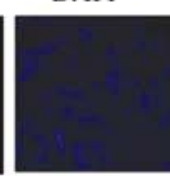

Merge
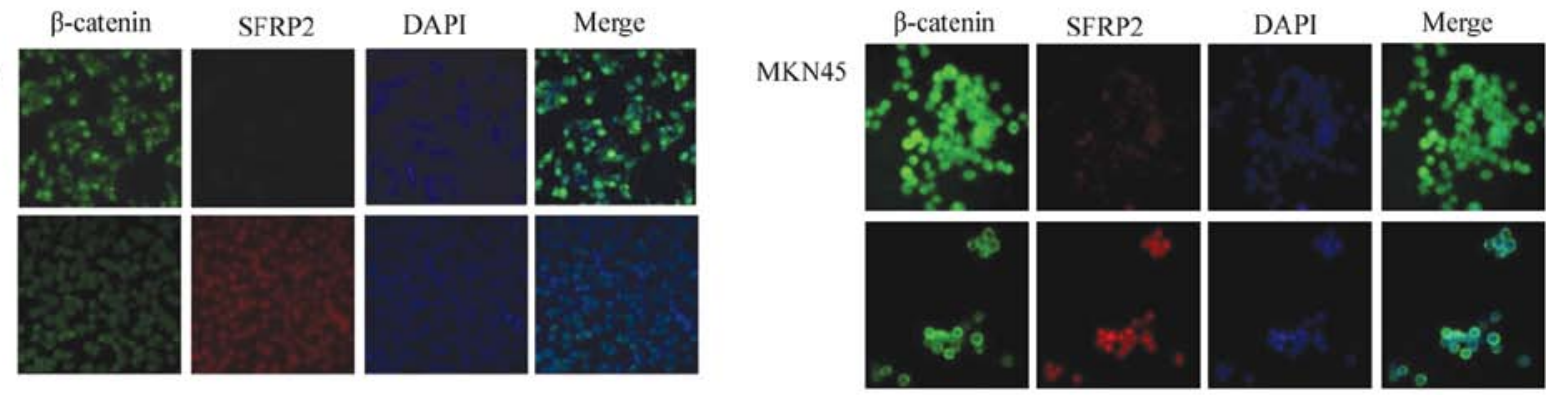

Figure 5. Decreased nuclear $\beta$-catenin expression due to butyrate treatment in human gastric cell lines. Immunofluorescence assay of the intracellular distribution of $\beta$-catenin in human gastric cell lines. Cells were stained with anti- $\beta$-catenin antibody (green) and anti-SFRP1/2 antibody (red). Nuclei were visualized using 40,6-diamidino-2-phenylindole (DAPI, blue).
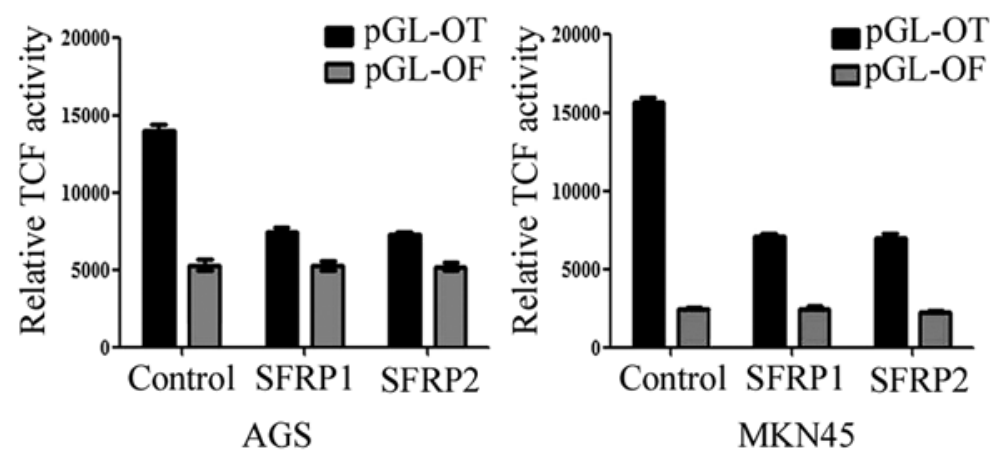

Figure 6. The Wnt signaling pathway in human gastric cancer cells can be suppressed by overexpression of SFRPs. Relative luciferase activity obtained using a TCF/LEF-responsive reporter (pGL3-OT) and a negative control (pGL3-OF) in GC cells transfected with the indicated SFRP1/2 expression constructs. Results are expressed as the pGL3-OT/pGL3-OF activity ratio after correction for transfection efficiency using renilla luciferase activity. Shown are means of four replications; the error bars represent standard deviations.

know histone deacetylase (HDAC) inhibitor including histone modification epigenetically, we saught to determine whether DNA methylation changes also contributed to SFRP activation by the sodium butyrate. To that purpose, the methylations of the SFRP1/2 promoter were analyzed with methylation specific PCR in human gastric cancer cell lines (Fig. 4B). We found that sodium butyrate treatment also induced promoter demethylation of SFRP genes in human gastric cancer cells along with histone modification as well. These finding suggest that sodium butyrate induces both promoter demethylation and histone modification epigenetically to activate SFRP gene expression in human gastric cancer cells.

Inhibition of the nuclear $\beta$-catenin expression by sodium butyrate treatment. To confirm the crosstalk between the nuclear $\beta$-catenin and SFRPs expression by sodium butyrate, immunofluorescence assay were performed in human gastric cancer cells $48 \mathrm{~h}$ after the treatment with sodium butyrate. Decreased nuclear $\beta$-catenin expression and increased SFRP expression was noted by sodium butyrate. These finding suggest that the increased SFRP expression correlated with the deceased nuclear $\beta$-catenin localization in sodium butyrate treated human gastric cancer cells (Fig. 5).

Suppression of TCF/LEF activity by SFRP overexpression. SFRP $1 / 2$ expression vector was transiently transfected to human gastric cancer cells (AGS and MKN45) with silencing of SFRP1 and 2. After $48 \mathrm{~h}$ of transfection, TCF/LEF activity was significantly decreased from $40 \%$ (AGS: SFRP1) $\left({ }^{*} \mathrm{P}<0.05\right), 37 \%$ (AGS: SFRP2) ( $\left.{ }^{*} \mathrm{P}<0.05\right), 33 \%$ (MKN45: SFRP1) $\left({ }^{*} \mathrm{P}<0.05\right)$, 


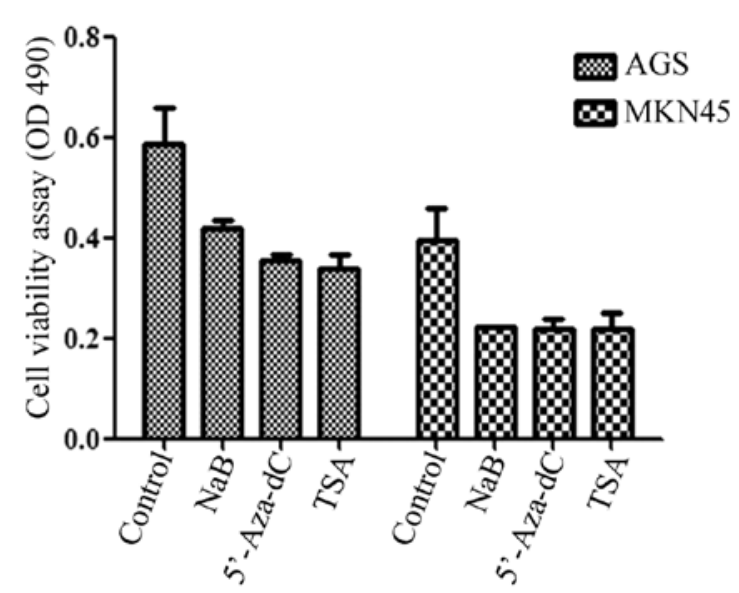

Figure 7. Treatment with sodium butyrate inhibits human gastric cancer cell proliferation. Cells were seeded in 96-well plates. The colorimetric MT assay was used to measure cell numbers at $48 \mathrm{~h}$. The experiment was performed in triplicate.

35\% (MKN45: SFRP2) ( $\left.{ }^{*} \mathrm{P}<0.05\right)$. These finding suggest that overexpression of either SFRP1 or SFRP2 suppressed TCF/LEF activity in human gastric cancer cells (Fig. 6).

SFRPs inhibit cell proliferation and induce cell apoptosis. To examined the effect of SFRP expression on cell proliferation and apoptosis in human gastric cancer cells. After $48 \mathrm{~h}$ of sodium butyrate treatment, cell viability was reduced from 0.65 to 0.42 (in AGS) ( $\left.{ }^{*} \mathrm{P}<0.05\right), 0.42$ to 0.22 (in MKN45) $\left({ }^{*} \mathrm{P}<0.05\right)$ (Fig. 7) as determined by cell proliferation assay. Cell apoptosis were also determined by counting sub-G1 phase cells in flow cytometry analysis. At $48 \mathrm{~h}$ of sodium butyrate treatment, cell apoptosis was significantly induced from 0.6 to $13.1 \%$ (in AGS) and 0.1 to $19.6 \%$ (in MKN45) respectively ( ${ }^{*} \mathrm{P}<0.05$ ) (Fig. 8A). Also at $48 \mathrm{~h}$ of SFRP overexpression by plasmid transfection, cell apoptosis was significantly induced from 0.06 to $23.4 \%$ (in AGS) and 0.04 to $14.1 \%$ (in MKN45) ( ${ }^{*} \mathrm{P}<0.05$ ) (Fig. 8B). These findings suggest that SFRP, as a tumor suppressor, inhibits cell proliferation and induces cell apoptosis in human gastric cancer.

\section{Discussion}

Several lines of evidence suggest the activation of the Wnt signal pathway also occurs in gastric cancer cell lines with varying degree of APC or $\beta$-catenin gene mutations (12-15). It was reported that $19.5 \%$ (59 of 303) of primary gastric cancer showed nuclear accumulation of $\beta$-catenin while $\beta$-catenin mutation was detected in only 5\% (4 of 77) of the cancers (37-39). Another group analysed 311 primary gastric cancers and observed nuclear $\beta$-catenin in $90(29 \%)$, but $\beta$-catenin mutations in only 19 of 73 cancers (26\%) with nuclear $\beta$-catenin, and no mutations were found in $19 \beta$-catenin without nuclear accumulation $(17,38)$.

In this study, we first sought to assess the role of Wnt signaling in human gastric cancer cells using several independent approaches. Using immunohistochemistry staining, we observed that nuclear $\beta$-catenin expression was higher in cancer tissues than adjacent non-cancer tissues by immunohistochemical examination of clinically cancer tissues. Western blot analysis showed detectable levels of $\beta$-catenin in human gastric cancer cells tested. However, the levels of nuclear $\beta$-catenin expression were much more varied and were not detected in one cell line (SNU1). These results suggested that the involvement of mechanisms other than Wnt related gene mutations in the activation of Wnt signaling in human gastric cancer cells. Hypermethylation can suppress the expression of important growth regulatory genes. Although the process driving aberrant methylation is not clear, it has been proposed that tissue inflammation and elevated rates of cell turnover may play an important role (18-20,31-33). SFRPs were down-regulated in human gastric cancer and may carry tumor suppressor potential $(21,23,24,40)$. The putative function of SFRPs as antagonist of the Wnt pathway provides a potential mechanism to suppress the abnormal activation of this pathway in vivo. To this end the evaluation of mechanisms of down-regulation of SFRP expression may also contribute to the suppression of Wnt signaling in human gastric cancer providing a potential anti-tumor target. We extended the study to determine the mRNA expression level and the methylation status of SFRPs in human gastric cancer. Surprisingly, none of the 9 human gastric cancer cell lines tested showed any expression of SFRP1/2 mRNA. Treatment with a
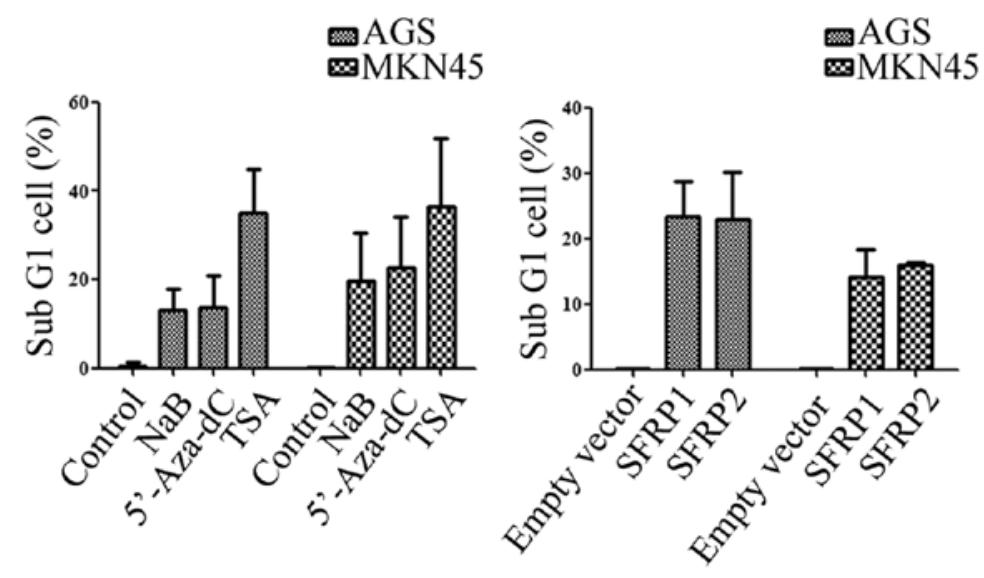

Figure 8. Apoptosis induced by SFRPs. (A) Quantification of flow cytometric result. Cells were harvested and analyzed 48 h after treatment with sodium butyrate. (B) Quantification of flow cytometric result. Cells were harvested and analyzed $48 \mathrm{~h}$ after transfection. Apoptotic cells are indicated as the sub-G1 fraction, and percentages are shown. 
DNA methyltransferase inhibitor, 5'-Aza-dC rapidly restored SFRPs expression. We observed SFRP methylation in all the human gastric cancer cell lines tested. These data suggested that alterations in SFRP1/2 may also be important determinants of the Wnt signaling in human gastric cancer $(12,25-27)$.

Various compounds have been shown to impact methylation, raising the possibility that an individual's diet may also influence DNA methylation $(28-30,33)$. Sodium butyrate is generated by the microbial metabolism of dietary fibers in the lower gastrointestinal tract and has been proposed to confer a number of health benefits including a reduced risk of colorectal cancer $(31,32,41)$. Here, we report that the sodium butyrate can reactivate SFRP expression in human gastric cancer cells, through epigenetic mechanism. Using western blot analysis significant change of total $\beta$-catenin level by sodium butyrate treatment in human gastric cancer cells was tested, and levels of nuclear $\beta$-catenin expression were siginificantly decreased in human gastric cancer cell lines. TCF/LEF-regulated transcription activity showed that $\beta$-catenin-TCF/LEF activity deceased with sodium butyrate treatment or SFRP overexpression. Immunofluorescence analysis showed the increased SFRP expression and suppression of nuclear $\beta$-catenin expression in sodium butyrate treated human gastric cancer cells. These findings suggest inhibition of the nuclear $\beta$-catenin translation and increased SFRP expression by sodium butyrate in human gastric cancer. Several tumor suppressor genes are known to be repressed by hypomethylated promoters $(33,34)$. These facts indicate that although DNA methylation is a major epigenetic mechanism for gene silencing, there are other epigenetic silencing pathways independent of DNA methylation (35). It is generally accepted that aberrant DNA methylation and histone modifications work together to silence many tumor suppressor genes in human cancer $(36,37)$. ChIP assay revealed that histone modification indeed were increased in human gastric cancer cells. These histone patterns are known as an open chromatin structure with associated with active gene expression. We examined the effect of a sodium butyrate on histone acetylation $(\mathrm{AcH} 3, \mathrm{AcH} 4), \mathrm{H} 3 \mathrm{~K} 4$ and $\mathrm{H} 3 \mathrm{~K} 9$ methylation associated with the SFRP $1 / 2$ promoter regions along with the effect of sodium butyrate on SFRP methylation status in human gastric cancer.

Our data suggested that: i) sodium butyrate cause SFRP promoter demethylation; generated a more sporadic pattern of demethylation; ii) DNA methylation and histone modifications of SFRP promoter region were strongly correlated with SFRP expression in human gastric cancer. Wnt signal activation by mutant $\beta$-catenin or APC could be suppressed partially by overexpression of SFRPs $(38-40,42,43)$. One recent study showed that SFRP1 is frequently methylated in prostate cancer, and ectopic expression of SFRP1 reduced cellular proliferation, even though $\beta$-catenin-TCF/LEF is not activated in prostate cancer cells (44). In another study, SFRP4 was found to be methylated in $\beta$-catenin-deficient mesothelioma cells, and overexpression of SFRP4 in the cells resulted in apoptosis and growth suppression $(45,46)$. We obtained similar results that expression of SFRPs in human gastric cancer cell lines inhibits cell proliferation and induces cell apoptosis. Our results suggest that the activation of Wnt signaling may occur without mutation of $\beta$-catenin or APC genes and this may be induced by down-regulation of SFRP in human gastric cancer cells. We found that human gastric cancer cells showed increased Wnt signal activity and the SFRP expression was down-regulated through epigenetic modification. Sodium butyrate did not complete demethylation but generated a more sporadic pattern of demethylation. DNA methylation and histone modifications at the SFRP promoter region were strongly correlated with SFRPs expression. Expression of SFRPs likely contributes to the proliferation and apoptosis of human gastric cancer cells. In conclusion, DNA methylation and histone modification act together to inhibit SFRP gene expression in human gastric cancer cell lines. Sodium butyrate may prove to be considerably effective at preventing cancer-induced changes in DNA methylation.

\section{Acknowledgements}

This study was supported by a grant of the Korea Health Technology R\&D Project, Ministry of Health \& Welfare Republic of Korea (A090955), and the authors wish to thank the Yonsei-Carl Zeiss Advanced Imaging Center, Yonsei University College of Medicine for technical assistance.

\section{References}

1. Esteller M: Aberrant DNA methylation as a cancer inducing mechanism. Annu Rev Pharmacol Toxicol 45: 629-656, 2005.

2. Esteller $\mathrm{M}: \mathrm{CpG}$ island hypermethylation and tumor suppressor genes: a booming present, a brighter future. Oncogene 21: 5427-5440, 2002.

3. Esteller M: Epigenetics provides a new generation of oncogenes and tumour-suppressor genes. Br J Cancer 96: R26-R30, 2007.

4. Fahrner JA, Eguchi S, Herman JG and Baylin SB: Dependence of histone modifications and gene expression on DNA hypermethylation in cancer. Cancer Res 62: 7213-7218, 2007.

5. Ballestar E, Paz MF, Valle L, Wei S, Fraga MF, Espada J, Cigudosa JC, Huang TH and Esteller M: Methyl-CpG binding proteins identify novel sites of epigenetic inactivation in human cancer. EMBO J 22: 6335-6345, 2003.

6. Rountree MR, Bachman KE, Herman JG and Baylin SB: DNA methylation, chromatin inheritance, and cancer. Oncogene 20: 3156-3165, 2000.

7. Jones PA and Baylin SB: The fundamental role of epigenetic events in cancer. Nat Rev Genet 3: 415-428, 2002.

8. Taketo MM: Shutting down Wnt signal-activated cancer. Nat Genet 36: 320-322, 2004

9. Kawano Y and Kypta R: Secreted antagonists of the Wnt signalling pathway. J Cell Sci 116: 2627-2634, 2003.

10. Hsieh JC, Kodjabachian L, Rebbert ML, Rattner A, Smallwood PM, Samos CH, Nusse R, Dawid IB and Nathans J: A new secreted protein that binds to Wnt proteins and inhibits their activities. Nature 398: 431-436, 1999.

11. Taipale $J$ and Beachy PA: The Hedgehog and Wnt signalling pathways in cancer. Nature 411: 349-354, 2001

12. Nojima M, Suzuki H, Toyota M, Watanabe Y, Maruyama R, Sasaki S, Sasaki Y, Mita H, Nishikawa N, Yamaguchi K, Hirata K, Itoh F, Tokino T, Mori M, Imai K and Shinomura Y: Frequent epigenetic inactivation of SFRP genes and constitutive activation of Wnt signaling in gastric cancer. Oncogene 26: 4699-4713, 2007.

13. Jones SE and Jomary C: Secreted frizzled-related proteins: searching for relationships and patterns. Bioessays 24: 811-820, 2002.

14. He J, Sheng T, Stelter AA, Li C, Zhang X, Sinha M, Luxon BA and Xie J: Suppressing wnt signal by the hedgehog pathway through SFRP1. J Biol Chem 281: 35598-35602, 2006.

15. Melkonyan HS, Chang WC, Shapiro JP, Mahadevappa M, Fitzpatrick PA, Kiefer MC, Tomei LD and Umansky SR: SARPs: a family of secreted apoptosis-related proteins. Proc Nal Acad Sci USA 94: 13636-13641, 1997.

16. Lehninger AL, Nelson DL and Cox MM: Principles of Biochemistry. 2nd edition. Worth, New York, 1993.

17. Widmer J, Fassihi KS, Schlichter SC, Wheeler KS, Crute BE, King N, Nutile-McMenemy N, Noll WW, Daniel S, Ha J, Kim KH and Witters LA: Identification of a second human acetyl-CoA carboxylase gene. Biochem J 316: 915-922, 1996. 
18. Medina V, Edmonds B, Young GP, James R, Appleton S and Zalewski PD: Induction of caspase-3 protease activity and apoptosis by butyrate and trichostatin A (inhibitors of histone deacetylase): dependence on protein synthesis and synergy with a mitochondrial/ cytochrome c-dependent pathway. Cancer Res 57: 3697-3707, 1997.

19. Richon VM,Emiliani S, Verdin E, Webb Y,Breslow R, Rifkind RA and Marks PA: A class of hybrid polar inducers of transformed cell differentiation inhibits histone deacetylases. Proc Natl Acad Sci USA 95: 3003-3007, 1998.

20. Wang J, Saunthararajah Y, Redner RL and Liu JM: Inhibitors of histone deacetylase relieve ETO-mediated repression and induce differentiation of AML1-ETO leukemia cells. Cancer Res 59: 2766-2769, 1999.

21. Butler LM, Agus DB, Scher HI, Higgins B, Rose A, CordonCardo C, Thaler HT, Rifkind RA, Marks PA and Richon VM: Suberoylanilide hydroxamic acid, an inhibitor of histone deacetylase, suppresses the growth of prostate cancer cells in vitro and in vivo. Cancer Res 60: 5165-5170, 2000.

22. Kim JH, Shin HS, Lee SH, Lee I, Lee YS, Park JC, Kim YJ, Chung JB and Lee YC: Contrasting activity of Hedgehog and Wnt pathways according to gastric cancer cell differentiation: Relevance of crosstalk mechanisms. Cancer Sci 101: 328-335, 2009.

23. Zhu WG, Dai Z, Ding H, Srinivasan K, Hall J, Duan W, VillalonaCalero MA, Plass C and Otterson GA: Increased expression of unmethylated CDKN2D by 5-aza-20-deoxycytidine in human lung cancer cells. Oncogene 20: 7787-7796, 2001.

24. Nakagawachi T, Soejima H, Urano T, Zhao W, Higashimoto K, Satoh Y, Matsukura S, Kudo S, Kitajima Y, Harada H, Furukawa K, Matsuzaki H, Emi M, Nakabeppu Y, Miyazaki K, Sekiguchi M and Mukai T: Silencing effect of $\mathrm{CpG}$ island hypermethylation and histone modifications on O6-methylguanine-DNA methyltransferase (MGMT) gene expression in human cancer. Oncogene 22: 8835-8844, 2003

25. Zhang Z, Joh K, Yatsuki H, Zhao W, Soejima H, Higashimoto K, Noguchi M, Yokoyama M, Iwasaka T and Mukai T: Retinoic acid receptor $\beta 2$ is epigenetically silenced either by DNA methylation or repressive histone modifications at the promoter in cervical cancer cells. Cancer Lett 247: 318-327, 2007.

26. Baylin SB, Hoppener JW, de Bustros A, Steenbergh PH, Lips CJ and Nelkin BD: DNA methylation patterns of the calcitonin gene in human lung cancers and lymphomas. Cancer Res 46: 2917-2922, 1984.

27. Kondo Y, Shen L and Issa JP: Critical role of histone methylation in tumor suppressor gene silencing in colorectal cancer. Mol Cell Biol 23: 206-215, 2003.

28. Goldberg AD, Allis CD and Bernstein E: Epigenetics: a landscape takes shape. Cell 128: 635-638, 2007.

29. Szyf M: Therapeutic implications of DNA methylation. Future Oncol 1: 125-135, 2005

30. Esteller M: Epigenetic gene silencing in cancer: the DNA hypermethylome. Hum Mol Genet 16: Spec No 1, R50-R59, 2007.

31. Ekbom A, Helmick C, Zack M and Adami HO: Ulcerative colitis and colorectal cancer. A population-based study. N Engl J Med 323: 1228-1233, 1990.

32. Issa JP, Ahuja N, Toyota M, Bronner MP and Brentnall TA: Accelerated age-related $\mathrm{CpG}$ island methylation in ulcerative colitis. Cancer Res 61: 3573-3577, 2001.

33. Fang M, Chen D and Yang CS: Dietary polyphenols may affect DNA methylation. J Nutr 137: S223-S228, 2007.
34. Milutinovic S, D'Alessio AC, Detich N and Szyf M: Valproate induces widespread epigenetic reprogramming which involves demethylation of specific genes. Carcinogenesis 28: 560-571, 2007.

35. Ou JN, Torrisani J, Unterberger A, Provençal N, Shikimi K, Karimi M,Ekström TJ and Szyf M: Histone deacetylase inhibitor Trichostatin A induces global and gene-specific DNA demethylation in human cancer cell lines. Biochem Pharmacol 73: 1297-1307, 2007.

36. Dong E, Guidotti A, Grayson DR and Costa E: Histone hyperacetylation induces demethylation of reelin and 67-kDa glutamic acid decarboxylase promoters. Proc Natl Acad Sci USA 104: 4676-4681, 2007.

37. Wang XF, Qian DZ, Ren M, Kato Y, Wei Y, Zhang L, Fansler Z, Clark D, Nakanishi O and Pili R: Epigenetic modulation of retinoic acid receptor beta2 by the histone deacetylase inhibitor MS-275 in human renal cell carcinoma. Clin Cancer Res 11: 3535-3542, 2007.

38. Clements WM, Wang J, Sarnaik A, Kim OJ, MacDonald J, Fenoglio-Preiser C, Groden J and Lowy AM: Beta-catenin mutation is a frequent cause of Wnt pathway activation in gastric cancer Cancer Res 62: 3503-3506, 2002.

39. Woo DK, Kim HS, Lee HS, Kang YH, Yang HK and Kim WH: Altered expression and mutation of beta-catenin gene in gastric carcinomas and cell lines. Int J Cancer 95: 108-113, 2001.

40. To KF, Chan MW, Leung WK, Yu J, Tong JH, Lee TL, Chan FK and Sung JJ: Alterations of frizzled (FzE3) and secreted frizzled related protein (hSFRP) expression in gastric cancer. Life Sci 4: 483-489, 2001

41. Boffa LC, Lupton JR, Mariani MR, Ceppi M, Newmark HL, Scalmati A and Lipkin M: Modulation of colonic epithelial cell proliferation, histone acetylation, and luminal short chain fatty acids by variation of dietary fiber (wheat bran) in rats. Cancer Res 52: 5906-5912, 1992.

42. Suzuki H, Gabrielson E, Chen W, Anbazhagan R, van Engeland M, Weijenberg MP, Herman JG and Baylin SB: A genomic screen for genes upregulated by demethylation and histone deacetylase inhibition in human colorectal cancer. Nat Genet 2: 141-149, 2002.

43. Suzuki H, Watkins DN, Jair KW, Schuebel KE, Markowitz SD, Chen WD, Pretlow TP, Yang B, Akiyama Y, van Engeland M, Toyota M, Tokino T, Hinoda Y, Imai K, Herman JG and Baylin SB: Epigenetic inactivation of SFRP genes allows constitutive WNT signaling in colorectal cancer. Nat Genet 4: 417-422, 2004.

44. Lodygin D, Epanchintsev A, Menssen A, Diebold J and Hermeking H: Functional epigenomics identifies genes frequently silenced in prostate cancer. Cancer Res 65: 4218-4227, 2005.

45. He B, Reguart N, You L, Mazieres J, Xu Z, Lee AY, Mikami I, McCormick F and Jablons DM: Blockade of Wnt-1 signaling induces apoptosis in human colorectal cancer cells containing downstream mutations. Oncogene 24: 3054-3058, 2005.

46. Kawamoto K, Hirata H, Kikuno N, Tanaka Y, Nakagawa M and Dahiya R: DNA methylation and histone modifications cause silencing of Wnt antagonist gene in human renal cell carcinoma cell lines. Int J Cancer 123: 535-542, 2008. 